\title{
Contributing Factors to Poor Functional Recovery after Delayed Nerve Repair: Prolonged Axotomy
}

\author{
Susan Y. Fu and Tessa Gordon \\ Department of Pharmacology and Division of Neuroscience, University of Alberta, Edmonton, Alberta, Canada T6G \\ 2S2
}

The contribution of prolonged motoneuron axotomy to the poor functional recovery after delayed nerve repair was determined by means of a nerve cross-anastomosis paradigm in the rat. The tibial nerve was axotomized up to 12 months before it was cross-sutured to the distal stump of the freshly cut common peroneal nerve to innervate the freshly denervated tibialis anterior muscle. Three to 17 months later, muscle and motor unit (MU) forces were measured to quantify the number of axons that had successfully regenerated and reinnervated the muscle. The extent of axonal branching was estimated by the innervation ratio (IR) (i.e., the number of muscle fibers innervated by each axon), which was obtained directly by counting muscle fibers in a single glycogen-depleted MU in each muscle and indirectly by calculation. The total number of MUs in each muscle significantly decreased with progression of axotomy and was only $35 \%$ of the control when axotomy was prolonged more than 3 months. Concurrently, MU force and IR increased exponentially, with a mean increase of threefold when axotomy was more than 3 months, which largely compensated for the reduction in the number of axons that reinnervated the muscle. Consequently, muscles reinnervated by tibial motor axons that had been axotomized up to 12 months produced as much force as those reinnervated by freshly axotomized tibial motor axons. Muscle weight, size, and muscle fiber size were similar to those after immediate nerve suture. Although prolonged axotomy does not compromise the number of muscle fibers innervated by each axon, it does reduce the capacity of motor axons to regenerate and thus is an important contributing factor to the poor functional recovery in delayed nerve repair.

[Key words: long-term axotomy, regeneration, reinnervation, motor units, innervation ratio, branching]

Nerve regeneration and recovery of target function in humans are often disappointing, even after microsurgical repair of injured nerves (Sunderland, 1978; Terzis and Smith, 1990). In par-

\footnotetext{
Received Aug. 1., 1994; revised Dec. 5, 1994; accepted Dec. 7, 1994.

We thank the Muscular Dystrophy Association and Medical Research Council of Canada for their support, the Alberta Heritage Foundation for Medical Research for supporting T.G. as research scientist, Rick Hansen Man-in Motion Legacy Fund for supporting S.Y.F. as a research fellow, and Dr. Keir Pearson for his helpful suggestions on the manuscript. This work partially fulfilled the requirements for S.Y.F.'s Ph.D. thesis, for which Dr. Irvine McQuarrie was the external examiner

Correspondence should be addressed to Dr. Susan Y. Fu, 424 Heritage Medical Research Building, University of Alberta, Edmonton, Alberta, Canada T6G 2S2.

Copyright $(1995$ Society for Neuroscience 0270-6474/95/153876-10\$05.00/0
}

ticular, regenerative outcome may be dismal when reinnervation of denervated target organs is delayed due either to a long distance between target and lesion site or to delayed nerve repair following major trauma (Sunderland, 1978; Merle et al., 1986; Birch and Raji, 1991).

The causes for the poor functional recovery after delayed nerve repair are not well understood. Three factors must be considered for optimal recovery. First, neurons must survive and synthesize material for axonal regeneration (Grafstein and McQuarrie, 1978). Second, the distal nerve stump and its nonneural cells must provide adequate trophic and substrate support for nerve regeneration (Ramon y Cajal, 1928; Holmes and Young, 1942). Third, regenerating axons must make functional connections with appropriate peripheral target(s) and the target organ must fully recover from denervation atrophy (Thomas et al., 1987; Gordon, 1994).

Unlike dorsal root ganglion neurons and cranial motoneurons (Aldskogius and Arvidsson, 1978; Arvidsson and Aldskogius, 1982; Himes and Tessler, 1989), axotomized spinal motoneurons in adults survive for long periods of time (Carlsson et al., 1979; Melville et al., 1989; Gordon et al., 1991). The capacity of in jured nerves to regenerate and the ability of denervated muscles to accept reinnervation after delayed nerve repair were first studied half a century ago (Holmes and Young, 1942; Gutmann and Young, 1944). In order to separately prolong axotomy or denervation, Young and his colleagues used a cross-nerve anastomosis regime in the rabbit hindlimb. Holmes and Young (1942) reported that the number of axonal sprouts in the distal nerve stump, 1 month after suturing the long-term axotomized tibial nerve to a freshly cut common peroneal nerve, was the same as after immediate nerve suture. Since the rate of sensory nerve regeneration was also the same in the two cases, the authors concluded that long-term axotomy did not compromise nerve regeneration. Because Gutmann and Young (1944) observed a progressive failure of muscle reinnervation after prolonged muscle denervation, poor functional recovery after delayed nerve repair has been attributed to the inability of denervated muscle to accept reinnervation and to recover from denervation atrophy (see also Bowden and Gutmann, 1944). However, it remains unknown whether long-term axotomy is detrimental to functional recovery.

Although regenerating axons can grow into the distal nerve stump (Holmes and Young, 1942), it is possible that after longterm axotomy they fail to elongate over the distance required to reach denervated muscle and/or to make functional nerve-muscle connections. An electrophysiological motor unit (MU) counting technique has enabled us to address whether long-term ax- 

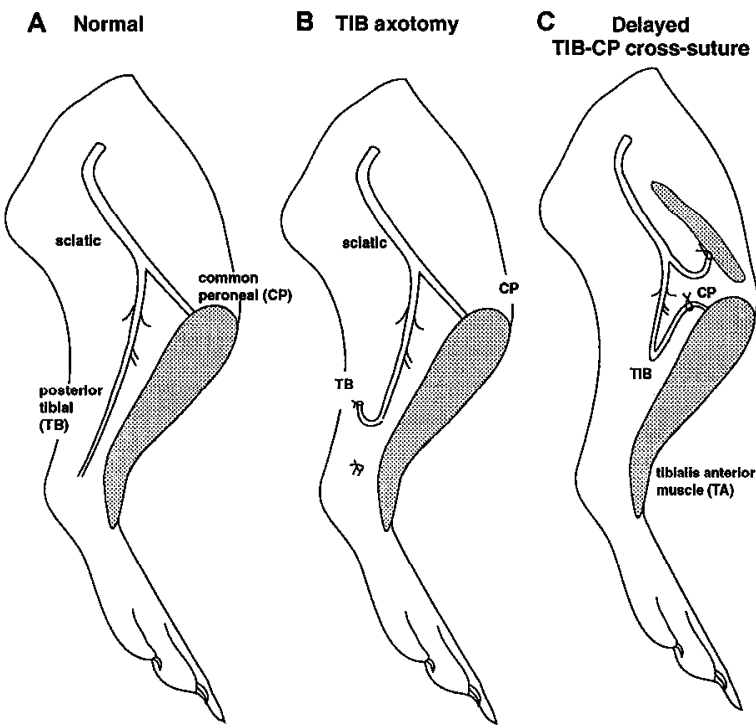

Figure 1. Diagrammatic illustration of neural innervation of TA muscle, tibial nerve axotomy, and TIB-CP cross-suture. $A$, The sciatic nerve normally branches into the common peroneal $(\mathrm{CP})$ nerve and posterior tibial (TIB) nerve. The CP nerve innervates muscles in the anterior compartment of the hindlimb including the tibialis anterior (TA) muscle (darkened). TIB nerve innervates the intrinsic muscles of the foot (not shown). $B$, The TIB nerve was cut and its proximal stump was prevented from regeneration hy ligation and suturing to the innervated triceps surae muscle for 0 to 12 months. $C$, Up to 1 year later, the $\mathrm{CP}$ nerve was cut and its proximal stump ligated and sutured to biceps femoris muscle to prevent self-reinnervation of TA muscle. In the same operation, the proximal TIB stump was refreshed and sutured to the freshly cut distal CP stump to promote TIB nerve regeneration and cruss-reinner valion of TA muscle.

otomy reduces the capacity of axons to regenerate and make functional nerve-muscle connections. The same nerve crossanastomosis paradigm described above was used in the present study to prolong motoneuron axotomy prior to nerve suture independent of the duration of muscle denervation. Electrophysiological and morphological methods were used to quantify the number of regenerating motor axons that successfully reinnervated freshly denervated muscle fibers, the number of muscle fibers reinnervated by one motor axon (the innervation ratio, IR) in one glycogen-depleted MU per muscle, the average IR for all the MUs in each muscle, and the capacity of long-term axotomized motoneurons to reverse dencrvation atrophy. The present results show that long-term axotomy does reduce the number of motor axons that successfully reinnervate freshly denervated muscle but not the number of muscle fibers reinnervated by each motor axon.

Some of these results have been described in abstract form (Fu and Gordon, 1993; Fu et al., 1993).

\section{Materials and Methods}

\section{Delayed nerve cross-anastomosis}

Under general anesthesia induced by intraperitoneal injection of sodium pentobarbital $(45 \mathrm{mg} / \mathrm{kg}$ ) and aseptic conditions, the posterior tibial (TIB) nerve on the right side was transected near the ankle in 32 female Sprague-Dawley rats (body weight, $150-200 \mathrm{gm}$ ). The site of section was distal to the exits of branches to the triceps surae, the plantaris, the flexor hallicis longus, and the flexor digitorum longi muscles. As shown in Figure 1, the proximal stump of the cut TIB nerve was either immediately cross-sutured to the distal stump of the cut common peroneal (CP) nerve close to the knee (immediate nerve-nerve suture) or ligated and sutured to the normally innervated lateral gastrocnemius muscle to
A
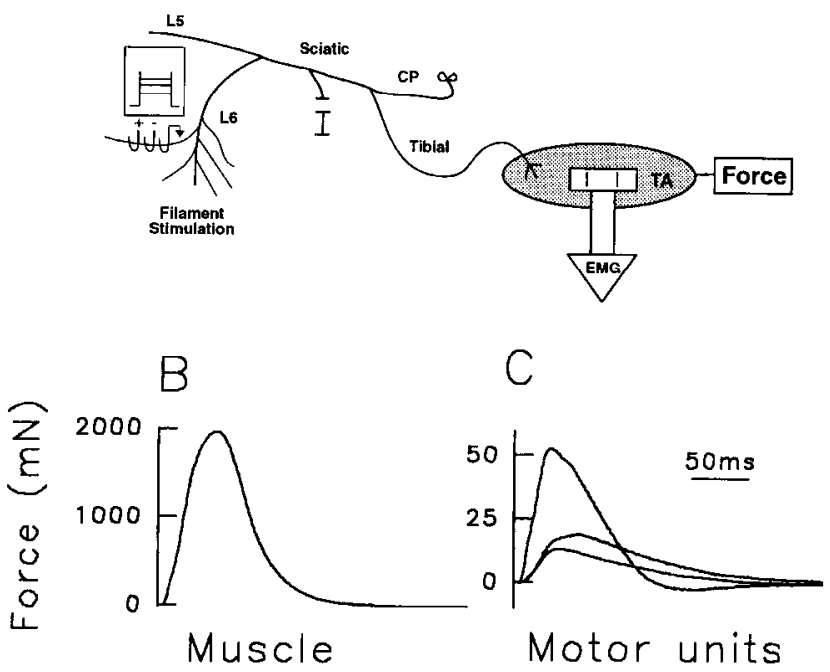

Figure 2. Muscle and motor unit (MU) twitch force recordings and the method used to calculate the number of MUs. A. Tibialis anterior (TA) muscle was isolated by denervating all other hindlimb muscles and attached to a force transducer. Ventral roots L5-L6 were isolated and split for stimulation of single motor axons contributing to TA muscle. $B$, Twitch contraction of the whole muscle was elicited by maximal nerve stimulation. $C$, Ventral root filaments were teased so that stimulation elicited all-or-none increments of force in the TA muscle. Shown in this example, twitch contractions of three individual MUs were obtained by digital substraction. The total number of MUs in each muscle was calculated by dividing muscle twitch force by the mean MU twitch force. For example, when muscle twitch force is $1990 \mathrm{mN}$ and the mealı MU twitch force is $14 \mathrm{mN}$, the calculated MU number should be 140 .

prevent its regeneration up to 1 year (Watson, 1970). A second surgery was performed 14-365 d later under general anesthesia. Absence of regeneration of the ligated TIB nerve was assured by the lack of foot movement in response to electrical stimulation of the proximal TIB nerve stump and the absence of reflex sensory response when stimulation was applied distal to the proximal stump of TIB nerve. The distal stump of TIB nerve was also pinched with a fine forceps and absence of reflex sensory response was regarded as lack of sensory reinnervation (Gutmann et al., 1942). Then, the proximal TIB nerve stump was refreshed (by removing $5 \mathrm{~mm}$ from the ligation site) and sutured to the distal stump of a CP nerve, which was freshly cut close to the anterior muscle compartment of the hindlimb (delayed nerve-nerve suture). The proximal stump of the $\mathrm{CP}$ nerve was ligated and sutured to the normally innervated biceps femoris muscle to prevent self-reinnervation of the tibialis anterior (TA) muscle.

\section{Surgical preparation for the final experiment}

From 3 to 17 (mean \pm SE, $11.9 \pm 0.8$ ) months after TIB-CP crosssuture, the TA muscle was isolated in a final experiment for muscle and MU force recordings. From 3 to $5 \mathrm{~d}$ prior to the final experiment, $5 \%$ glucose was added to the drinking water to increase muscle glycogen General anesthesia was again induced, monitored by continuous ECG recording and maintained by intravenous injection of $5 \%$ of the original sodium pentobarbital dose diluted $20 \%$ in $5 \%$ dextrose-saline via a cannula inserted into the right external jugular vein. Atropine sulphate $(0.1$ $\mathrm{mg} / \mathrm{kg}$ ) was injected to reduce tracheal secretion. The trachea was cannulated for mechanical ventilation when necessary. Blood volume was maintained by hourly injection of $0.5-1 \mathrm{ml}$ of the $5 \%$ dextrose-saline solution via the intravenous cannula.

All hindlimb, hip, and tail muscles innervated by L4-L6 ventral roots were denervated except the TA (Fig. 2A). Both the left and right TA muscles were isolated with their distal tendons attached to small pieces of bone for later attachment to force transducers. Bipolar surface patch electrodes were sewn onto the muscle fascia for either EMG recordings 
or direct muscle stimulation (Fig. $2 A$ ). The bared ends of two Tefloncoated fine silver wires, used as stimulating electrodes, were inserted into the muscle beneath the sciatic nerve for eliciting TA muscle contractions. Both hindlimbs were immobilized at the knees and ankles. The distal TA tendon was attached to a custom-made force transducer for recording muscle and $\mathrm{MU}$ forces. Leg and rectal temperatures were maintained at $30-32^{\circ} \mathrm{C}$ and $35-37^{\circ} \mathrm{C}$, respectively, with a heating pad and overhead electric bulb.

A laminectomy was performed from T13 to L6. The dura mater was cut. L4 L6 ventral roots were isolated with a glass rod and gentle suction using glass pipette. A mineral oil pool was prepared for the spinal cord and the exposed ventral roots by stretching the skin flaps around the incision. Stimulating electrodes for ventral roots were placed above the spinal cord in the mineral oil pool.

\section{Muscle and motor unit force recordings}

Force and EMG signals were amplified, monitored on a Tektronix dual time base oscilloscope (model 5441), recorded continuously on a Gould $1200 \mathrm{~S}$ pen recorder, and digitized and stored with an LSI- 11 computer.

The TA muscle was adjusted to its optimal length for recording maximum isometric twitch and tetanic forces in response to suprathreshold stimulation of the sciatic nerve. Twitch (Fig. $2 B$ ) and tetanic contractions were evoked by single stimulus and tetanic trains of 5 and 21 pulses at $100 \mathrm{~Hz}$ repeated at a frequency of $1 \mathrm{~Hz}$ for on-line computer averaging with EMG signals. Two to five EMG and force responses were averaged. Fine filaments containing three to seven axons in the ventral roots $\mathrm{L} 4, \mathrm{~L} 5$, and $\mathrm{L} 6$ contributing to the TIB nerve were stimulated to elicit all-or-none EMG and incremental force responses. Three to 10 EMG and twitch force responses to $1 \mathrm{~Hz}$ stimulation were averaged per increment, and the twitch response of each MU was obtained by digital subtraction (Fig. $2 C$ ). From 10 to $50 \mathrm{MUs}$ in each reinnervated TA muscle were sampled, which represented at least $30 \%$ (and up to $100 \%$ ) of the total MU population in each muscle.

One MU per muscle was isolated for characterization and glycogen depletion. MUs were classified as slow (S), fatigue resistant (FR), fast fatigue intermediate (FI), and fast fatigable (FF) on the basis of contractile speed, "sag" and fatigability (for details, see Tötösy de Zepetnek et al., 1992a). The criteria used for single MU isolation were an all-or-none twitch contraction and associated EMG response. A single MU was only selected for further characterization if the threshold voltage of its axon was less than $10 \mathrm{~V}$ and at least 10 times lower than the thresholds for any other motor axons innervating the TA muscle in the same ventral root filament. These criteria were rigidly met in order to keep a $\mathrm{MU}$ for $1-4 \mathrm{hr}$ of recordings and glycogen depletion. The isolated axon for a single MU was stimulated repetitively using trains of stimuli to deplete its glycogen content. Details of the stimulation protocol have been described (Tötösy de Zepetnek et al., 1992b). Briefly, MUs were stimulated up to $4 \mathrm{hr}$ with as many as 10 repeated cycles of brief $50 \mathrm{~Hz}$ tetanic trains (five pulses at an interval of $20 \mathrm{msec}$ ). In each cycle, the $\mathrm{MU}$ was stimulated with five pulses at $50 \mathrm{~Hz}$ at progressively higher repetition rates (from 1 to $9 \mathrm{~Hz}$ ) until force declined to less than $20 \%$. The contractile force was then allowed to recover using a low repetition rate of $0.25 \mathrm{~Hz}$.

\section{Muscle fiber histochemistry}

After completion of the glycogen depletion, the TA muscle was quickly removed, weighed, cut into three blocks, rapidly frozen in isopentane cooled with liquid nitrogen, and stored in a freezer at $-70^{\circ} \mathrm{C}$. Serial cross sections ( $10 \mu \mathrm{m}$ thick) were then cut and stained for (1) glycogen with Periodic Acid Schiff (PAS) reaction according to Pearse (1960), (2) myofibrillar ATPase after acid preincubation according to Green et al. (1982) and after preincubation at $\mathrm{pH} 10.4$ modified from Guth and Samaha (1970), and (3) nicotinamide adenine dinucleotide diaphorase (NADH) according to Dubowitz and Brooke (1973). Muscle fibers were classified into slow oxidative (SO), fast oxidative glycolytic (FOG), and fast glycolytic (FG), as previously described (Tötösy de Zepetnek et al., 1992b).

\section{Data analysis}

Motor unit number. At least $30 \%$ of the total MU population in each muscle was sampled to obtain a representative mean of MU twitch forces. The total number of MUs in each muscle was calculated by dividing the whole muscle twitch force by the mean MU twitch force (Jansen and Fladby, 1990; McComas, 1991).
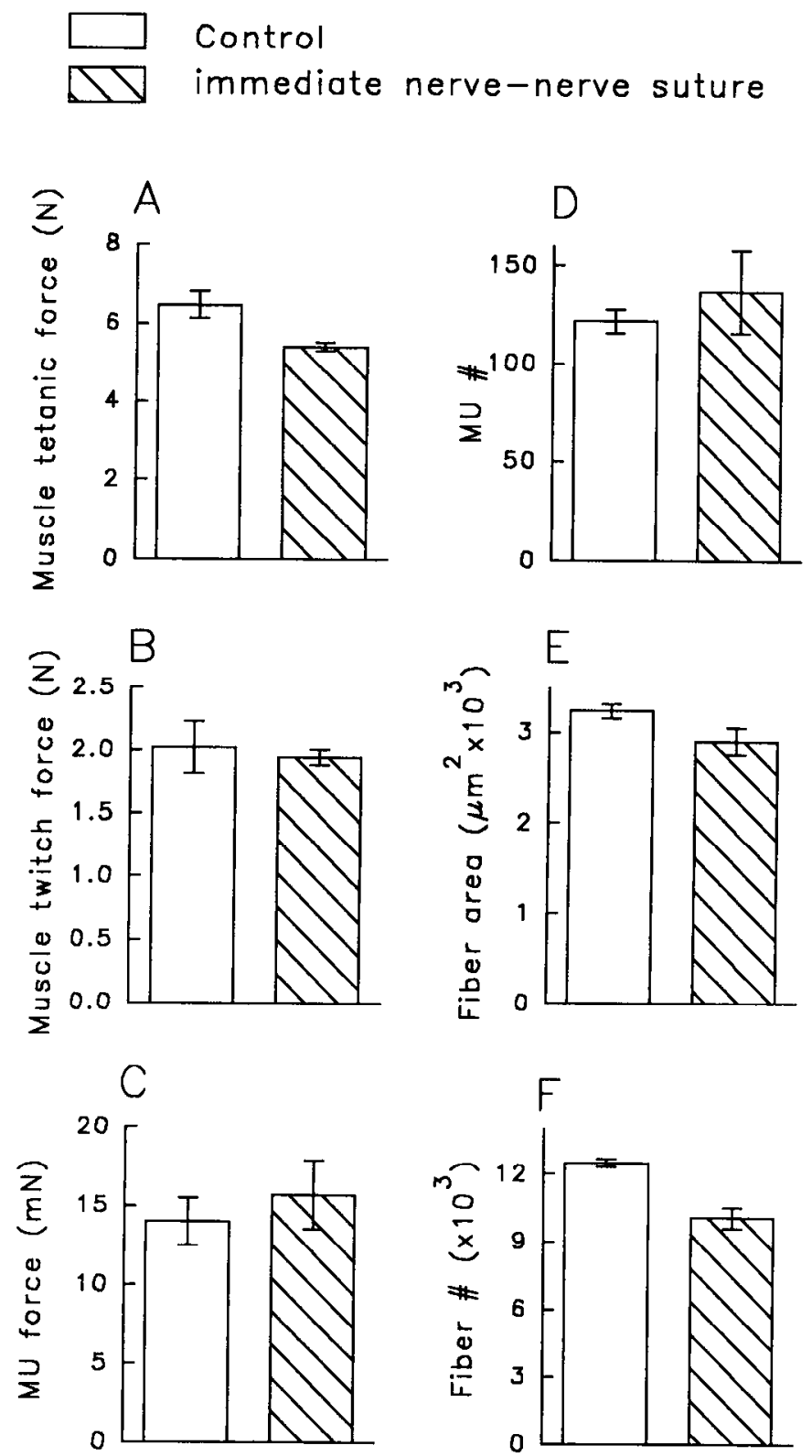

Figure 3. Mean ( $\pm \mathrm{SE}$ ) muscle force, MU force and number, muscle fiber size and number in cross-reinnervated TA muscles after immediate nerve cross-suture (cross-hatched bars) are compared with those in normal TA muscles in control rats (open bars). Cross-reinnervated muscles developed less tetanic force than control muscles $(p<0.05 ; A)$ and contained fewer muscle fibers $(p<0.05 ; F)$.

Muscle fiber number and size. The total number of muscle fibers in each muscle was calculated by multiplying muscle cross-sectional area (CSA) by muscle fiber density. Muscle CSA was measured on cross sections that contained the maximum number of muscle fibers. In the same cross sections, muscle fibers were counted in $0.63 \mathrm{~mm}^{2}$ areas located in the same comparable six to nine regions in all the muscles. The counting area included at least $10 \%$ of the total number of muscle fibers in each muscle. Muscle fiber density was measured in the same six to nine regions in order to take into account the regional difference in fiber size (Pullen, 1977; Parry and Wilkinson, 1990; Tötösy de Zepetnek et al., 1992a). The remaining error due to region selection was estimated by counting the number and size of muscle fibers in the same regions of both the left and right TA muscles in three control rats. The difference between the left and right sides was less than $10 \%$.

The average muscle fiber CSA was obtained by dividing the total muscle CSA by the total number of muscle fibers in each muscle. In 

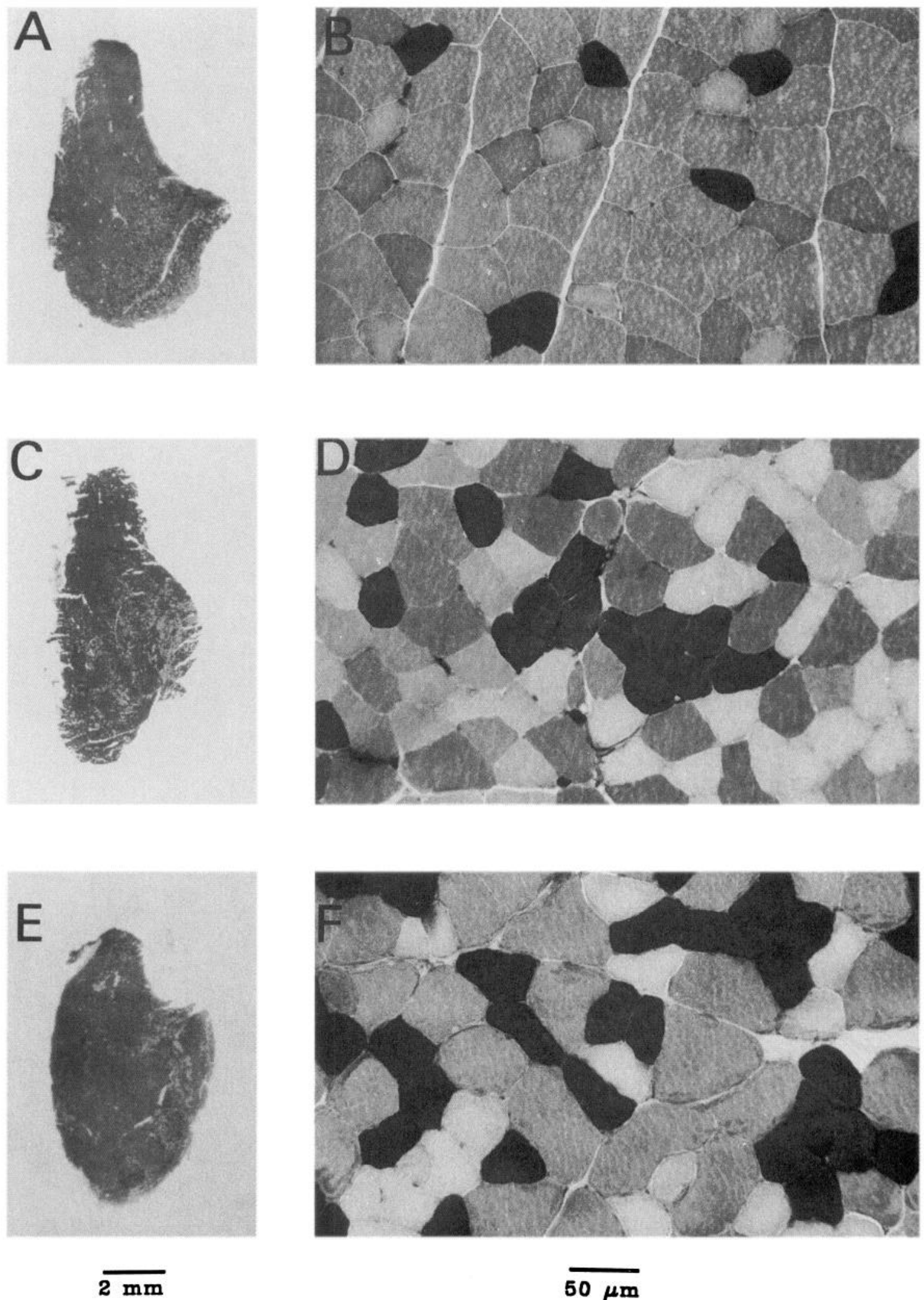

\section{$50 \mu \mathrm{m}$}

Figure 4. Low- and high-power photomicrographs of cross sections of control $(A$ and $B)$, cross-reinnervated TA muscle after immediate nerve suture $(C$ and $D)$, and cross-reinnervated TA muscle after nerve-nerve suture following long-term axotomy (12 months) $(E$ and $F)$ stained for mATPase with acid preincubation. The total cross-sectional area of the reinnervated muscle after prolonged axotomy was similar to those after both immediate nerve suture and control. Reinnervated muscle fibers of the same histochemical types tend to clump, but their size was not visually different from the control. Fibers in ascending intensity are type IIA (lightest), IIB (faint), Fint (intermediate), and type I (dark). 
order to validate this estimate, the calculated muscle CSA was compared with the directly measured fiber CSA of 500-1000 fibers within the six to nine regions in four reinnervated muscles. Good agreement was found between direct measurement $\left(2912 \pm 63 \mu \mathrm{m}^{2}\right)$ and indirect estimate of the mean muscle fiber CSA $\left(2985 \pm 166 \mu \mathrm{m}^{2}\right)$. The indirect method was therefore conventionally used to acquire the mean muscle fiber CSA in all control and cross-reinnervated $\mathrm{T} \Lambda$ muscles.

\section{Statistics}

Arithmetic means were calculated and shown with standard errors (mean \pm SE). One-way analysis of variance (ANOVA) was applied to examine differences for all the parameters (muscle force, MU number and force, muscle and muscle fiber number, and CSA) between control, cross-reinnervated muscles after immediate nerve repair and muscles that had been cross-reinnervated after different duration of axotomy. Bonferroni tests were used to detect any differences between all the possible combinations of paired conditions. The Kruskal-Wallis test of rank order was used to examine the differences in the distribution of muscle fiber CSA between control and cross-reinnervated muscles. Regression lines were fitted using least square analysis. For all the above statistical analyses, $p$ values $<0.05$ were regarded as significant.

\section{Results}

A total of 64 female rats was used in the study: 32 were unoperated controls and 32 underwent nerve cross-suture surgery in which the cut TIB nerve was sutured to the distal stump of the freshly cut CP nerve either immediately $(N=6)$ or after a delay of 14 to $365 \mathrm{~d}(N=26)$. Control muscle forces were recorded in normal TA muscles from age-matched unoperated rats $(N=$ 32; body weight, $291 \pm 70 \mathrm{gm})$. The final body weight of the operated rats was $344 \pm 9 \mathrm{gm}$ (range, $260-490 \mathrm{gm}$ ).

Muscle and MU forces were recorded in reinnervated TA muscles 3-17 months after TIB-CP cross-reinnervation because recovery of reinnervated TA muscles is stable by 3 months after nerve-nerve suture near the entry of $\mathrm{CP}$ nerve to the anterior muscle compartment of the hindlimb (Tötösy de Zepetnek et al., 1992a). The values of reinnervated muscle forces were compared with unoperated control TA muscles rather than contralateral TA muscles, which showed a concurrent compensatory hypertrophy associated with prolonged axotomy and TIB-CP cross-suture in the operated limb. Contralateral control TA muscles devcloped an average of $8102 \mathrm{mN}( \pm 224)$ tetanic force in rats in which cross-suture was delayed more than 6 months. This compares with $6470 \mathrm{mN}$ ( \pm 340 ) of normal unoperated TA muscles in age matched control rats.

\section{Immediate TIB-CP nerve cross-suture}

Reinnervated TA muscles developed smaller maximum tetanic forces than the control (Fig. $3 A$ ) in parallel with a small reduction in muscle weight $(545 \pm 68 \mathrm{gm}$ as compared to $627 \pm$ $154 \mathrm{gm}$ for the control; $p<0.05$ ). Twitch forces developed by the reinnervated muscles (Fig. $3 B$ ) and their MUs (Fig. $3 C$ ) were not different from the control $(p>0.05)$, assuciated with a higher twitch tetanic ratio in the reinnervated muscles. The higher ratio was, in turn, associated with the lower temperature of recording in the experimental rats than in the control rats 30 $32^{\circ} \mathrm{C}$ vs $34-35^{\circ} \mathrm{C}$ ). When muscle twitch force was divided by MU twitch force to obtain the MU number, it was evident that as many TIB motor axons reinnervated the TA muscle as the $\mathrm{CP}$ nerve normally does (Fig. $3 D$ ). Since the mean muscle fiber CSA was also the same as control (Fig. $3 E$ ), the small but significant reduction in the tetanic force of reinnervated muscles is due to a decrease in the number of muscle fibers (Fig. $3 F$ ).
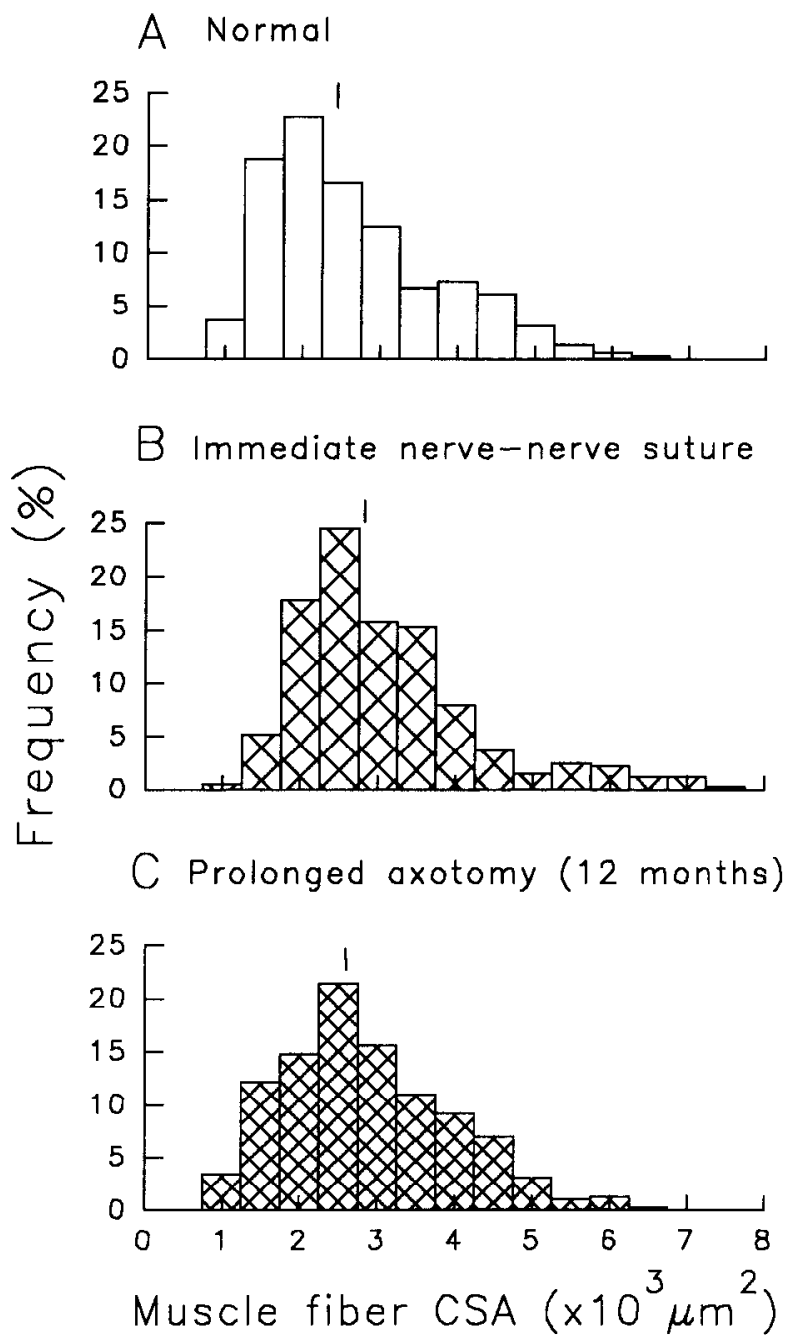

Figure 5. Frequency histograms of muscle fiber cross-sectional area (CSA) in one normal TA muscle $(A)$ and one cross-reinnervated TA muscle after immediate nerve suture $(B)$ and one cross-reinnervated TA muscle after 12 month TIB axotomy $(C)$. The mean muscle fiber CSAs ( \pm SE) (vertical lines) are $2401 \pm 47 \mu \mathrm{m}^{2}(A) ; 2853 \pm 49 \mu \mathrm{m}^{2}(B)$, and $2616 \pm 59 \mu \mathrm{m}^{2}(C)$.

\section{Prolonged TIB moloneuron axotomy}

When TIB motoneurons were axotomized up to 1 year prior to TIB-CP cross-sulure, the reinnervated TA muscles recovered as well as after immediate nerve suture. This was apparent from the size of the muscle (Fig. 4), CSA of muscle fibers (Figs. 4, 5) and mean muscle force (Fig. 6A). Muscle twitch and tetanic forces did not decline with prolonged axotomy prior to nerve suture (Fig. 6A). However, the number of reinnervated MUs declined exponentially $(\tau=40 \mathrm{~d}$ ) to less than $35 \%$ of the number in reinnervated muscles after immediate nerve-nerve suture when axotomy was prolonged more than 6 months (Fig. 6B).

MU enlargement compensated for the reduction in MU number. MU force increased by two to three times (Fig. 6C), and was accompanied by a similar increase in the number of muscle fibers per motoneuron (the innervation ratio, IR; Fig. $6 D$ ). The enlargement of MUs was sufficient to include all available denervated muscle fibers. As a result, the number of reinnervated muscle fibers was the same as after immediate nerve suture (Fig. $6 E$ ). Prolonged axotomy therefore compromised the ability of motor axons to regenerate and/or to make functional connections 

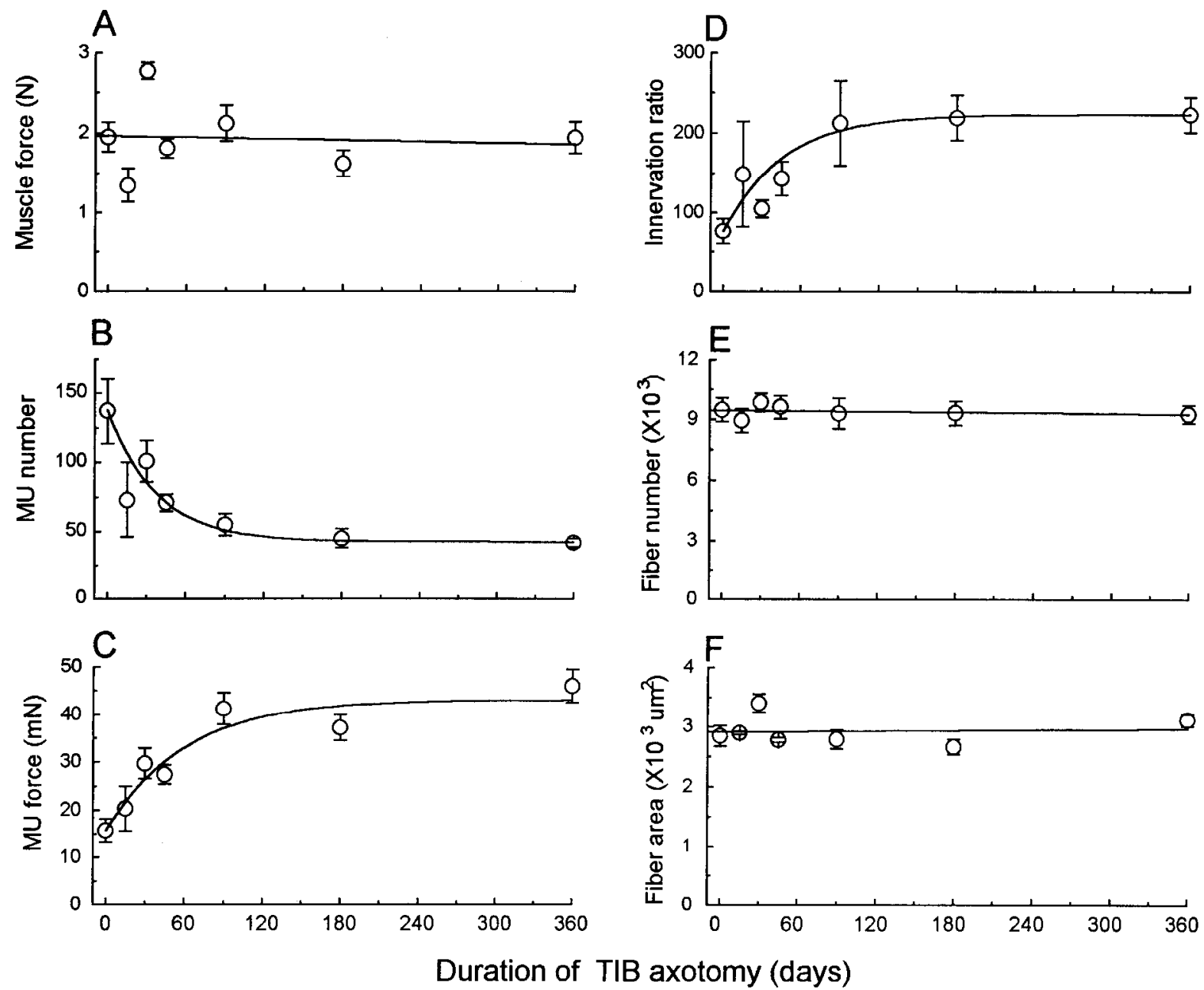

Figure 6. Effects of duration of TIB motoneuron axotomy prior to TIB-CP nerve cross-suture on mean ( \pm SE) muscle force $(A)$, MU number $(B)$, MU force $(C)$, innervation ratio $(D)$, the total number of muscle fibers $(E)$, and the size of muscle fibers $(F)$ in cross-reinnervated TA muscles. Regression lines fitted to the plots in $A, E$, and $F$ are not significantly different form zero, showing that muscle force, muscle fiber number, and muscle fiber size are not affected by prolonged axotomy. In contrast, the number of reinnervated MUs declined $(B)$ with a parallel increase in MU force $(C)$ and the innervation ratio $(D)$. The decline and increases were well fitted by exponential curves with time constants $(\tau)$ of 40,45 , and 57 d.

but not their ability to branch and to reinnervate denervated muscle fibers. In addition, prolonged axotomy did not compromise the recovery of normal muscle fiber size associated with reinnervation (Fig. $6 F$ ).

In summary, significantly fewer axons reinnervated denervated TA muscles but each axon reinnervated three times as many muscle fibers as after immediate nerve repair. As a result, as many muscle fibers were reinnervated as after immediate nerve suture despite the threefold reduction in MU number. Since all reinnervated muscle fibers recovered their normal size, muscle force was not significantly different from that after immediate nerve suture.

\section{Properties of the cross-reinnervated TA muscle}

Contractile speed of the cross-reinnervated TA muscles was not affected by prolonged axotomy even though there was a small but significant increase in the proportion of slow fibers in muscles reinnervated after 1 year of axotomy (Fig. 7; see also Fig. 4). Either there is some preferential reinnervation of the muscle fibers by $S$-type motoneurons or, alternatively, the functional overload of the muscles as a result of the cross-reinnervation leads to conversion of fast to slow muscle fibers (Gordon and Pattullo, 1993). The same order of IR found in normal muscles was preserved in the reinnervated muscles (Fig. 8), namely, $S$ $<\mathrm{FR}<\mathrm{FI}<\mathrm{FF}$, which is more consistent with the second suggestion. The small increase in the number of slow muscle fibers in cross-reinnervated muscles was not detected as an increased time to peak force in the whole muscle twitch consistent with the finding that increased numbers of slow MUs in reinnervated muscles alters the relaxation rate but not the rate of rise of twitch force (Gillespie et al., 1986).

As shown in Figure 8, MU twitch and tetanic forces correlated well with the number of muscle fibers reinnervated by each motoneuron (IR) and to a much lesser degree with mean MU fiber CSA and specific force. The slope of the regression line between force and IR was steeper than normal because MU force depends more on IR than on the mean CSA and specific force in crossreinnervated muscles as is truc in self-rcinncrvated muscles (Tötösy de Zepetnek et al., 1992a). Furthermore, the correlation between twitch force and IR is the same as that for tetanic force versus IR showing that MU twitch force is as good an indicator 

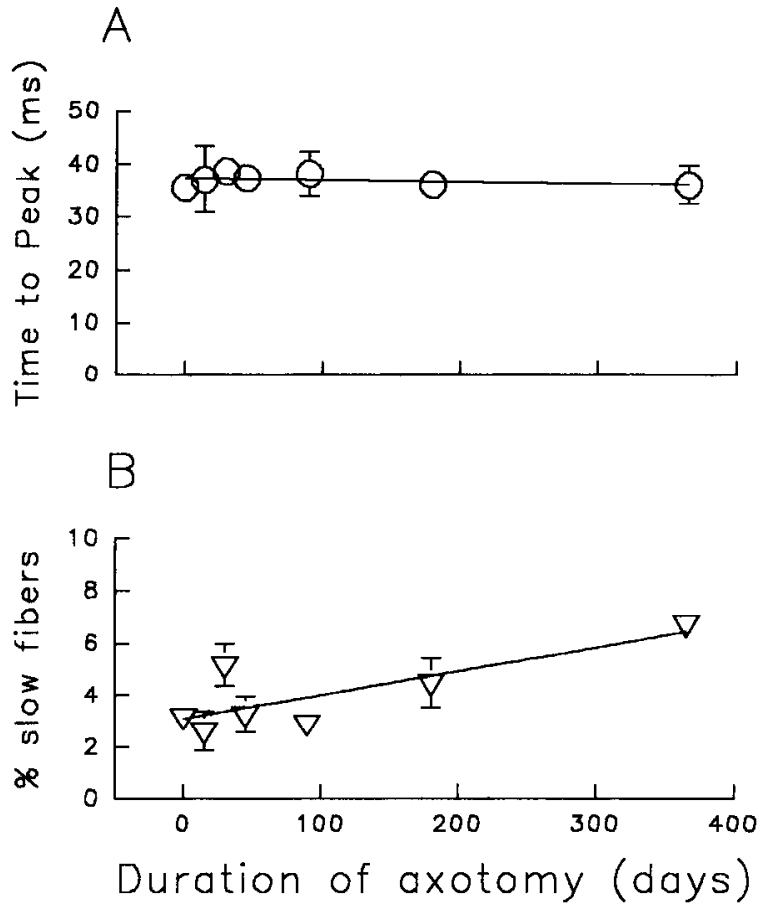

Figure 7. Mean $( \pm \mathrm{SE})$ time to peak twitch contractions $(A)$ and proportion of slow muscle fibers $(B)$ in cross-reinnervated TA muscles as a function of duration of TIB axotomy prior to TIB-CP cross-suture. Muscle contraction speed did not change as a result of progressively longer duration of axotomy, despite a small but significant increase in the proportion of slow muscle fibers $(p<0.05)$. The slopes $( \pm S E)$ of the regression lines in $A$ and $B$ were $0.004 \pm 0.004$ and $0.0092 \pm$ 0.003 , respectively.

as MU tetanic force for estimating MU size in terms of the number of muscle fibers reinnervated per motoneuron.

\section{Discussion}

The present results show that prolonged axotomy significantly reduces the number of motor axons that regenerate and make functional connections with denervated muscle fibers. Thus, prolonged axotomy is likely to be an important contributing factor to poor functional recovery observed in animal models and human patients when nerve repair is delayed. Nevertheless, prolonged axotomy does not compromise the capacity of regenerating axons to branch or the number of nuscle fibers reinnervated by each motor axon, as indicated by the increased IR that compensated for the reduced number of reinnervated MUs.

\section{MU number in the cross-reinnervated TA muscle}

An average of 137 TIB motoneurons made functional connections with each denervated TA muscle after immediate 'IIB-CP cross suture. This number is similar to the number of CP motoneurons that normally supply the TA muscle. This number, calculated from the ratio of muscle force and average $\mathrm{MU}$ force (Jansen and Fladby, 1990; McComas, 1991), is about a third of the 500-600 motoneurons that send their axons to the intrinsic muscles of the foot via the posterior TIB nerve and to the dorsiffexor muscles via the CP nerve (Swett et al., 1986; Crockett et al., 1987) and represents a large proportion of the 300-400 $\alpha$-motoneurons in the motor pools (Boyd and Davey, 1968). Considering that the regenerating TIB nerve supplies several flexor muscles in addition to TA, the TIB motor axons were very successful in reinnervating the TA muscle after immediate nerve suture.

When axotomy was prolonged for longer than 6 months prior to nerve cross suture, an average of 50 TIB motoneurons or onethird of the available motoneurons made functional connections with the freshly denervated TA muscle. Either the rest of the axons regenerated but did not succeed in reinnervating muscle fibers or they failed to grow over the distance required to reach the muscle. The former explanation is unlikely, because the axons that did succeed in reaching the denervated TA muscle reinnervated more muscle fibers than those axons that reinnervated IA after immediate nerve suture.

Our conclusion that prolonged axotomy reduces the motoneuron's capacity to regencratc is in apparent contrast to Holmes and Young's (1942) suggestion that the regenerative capacity of the central nerve stump does not diminish "during the progressive formation of a neuroma." In their study, the rabbit TIB nerve was cut and, 14-365 d later, cross-sutured to the distal stump of the freshly cut CP nerve at the level of the thigh rather than the ankle as in this study. The same number of regenerative sprouts were found in the freshly cut CP distal nerve stump when the TIB nerve was cut and sutured immediately as when the TIB nerve was ligated and sutured after a delay. However, the axonal counts were made $15-25 \mathrm{~d}$ after cross-suture and therefore reflect only the early outgrowth of sprouts from the proximal nerve stump. Each parent axons gives rise to an average of five daughter sprouts, of which only one normally remains once target connections are made (Aitken et al., 1947; Toft et al., 1988; Mackinnon et al., 1991). The withdrawal may take many months ( itken et al., 1947; MacKinnon et al., 1991) so that the early axonal counts are likely to greatly overestimate the number of axons that regenerate successfully over distance to make functional target connections. For motoneurons, physiological methods to count MUs provide a useful tool to quantify the number of axons that successfully regenerate and form functional nerve-muscle connections. MU estimates in the present study convincingly show that the number was significantly reduced after prolonged axotomy. Retrograde labeling of motoneurons in reinnervated muscles is an alternative for counting axons that reach the muscle, but the counts will inevitably include those axons that reach the muscle but do not form functional connections.

The number of regenerating axons that make functional connections declines as a function of the duration of axotomy prior to nerve suture. The decline was exponential with a time constant $(\tau)$ of $40 \mathrm{~d}$. The asymptotic level corresponds to $35 \%$ of the number after immediate nerve suture (Fig. 6B). Lumbar spinal motoneurons survive long-term axotomy (Gordon et al., 1991) but they may be sufficiently traumatized that a significant number fail to properly regenerate. It is also probable that the capacity of axotomized motoneurons to regenerate their axons progressively declines with prolongation of axotomy prior to refreshing the nerve in delayed nerve repair. Growth-associated events in axotomized motoneurons such as upregulation of tubulin and actin may not be optimally retained when regeneration is temporarily prevented (Cassar and Tetzlaff, 1991). Furthermore, growth attempts may be dissipated by formation of neuroma and subsequent axonal growth within it. Interestingly, long-term axotomized motoneurons show the same qualitative response to a second axotomy as in freshly axotomized motoneurons by upregulation of tubulin and GAP-43 mRNA, down- 

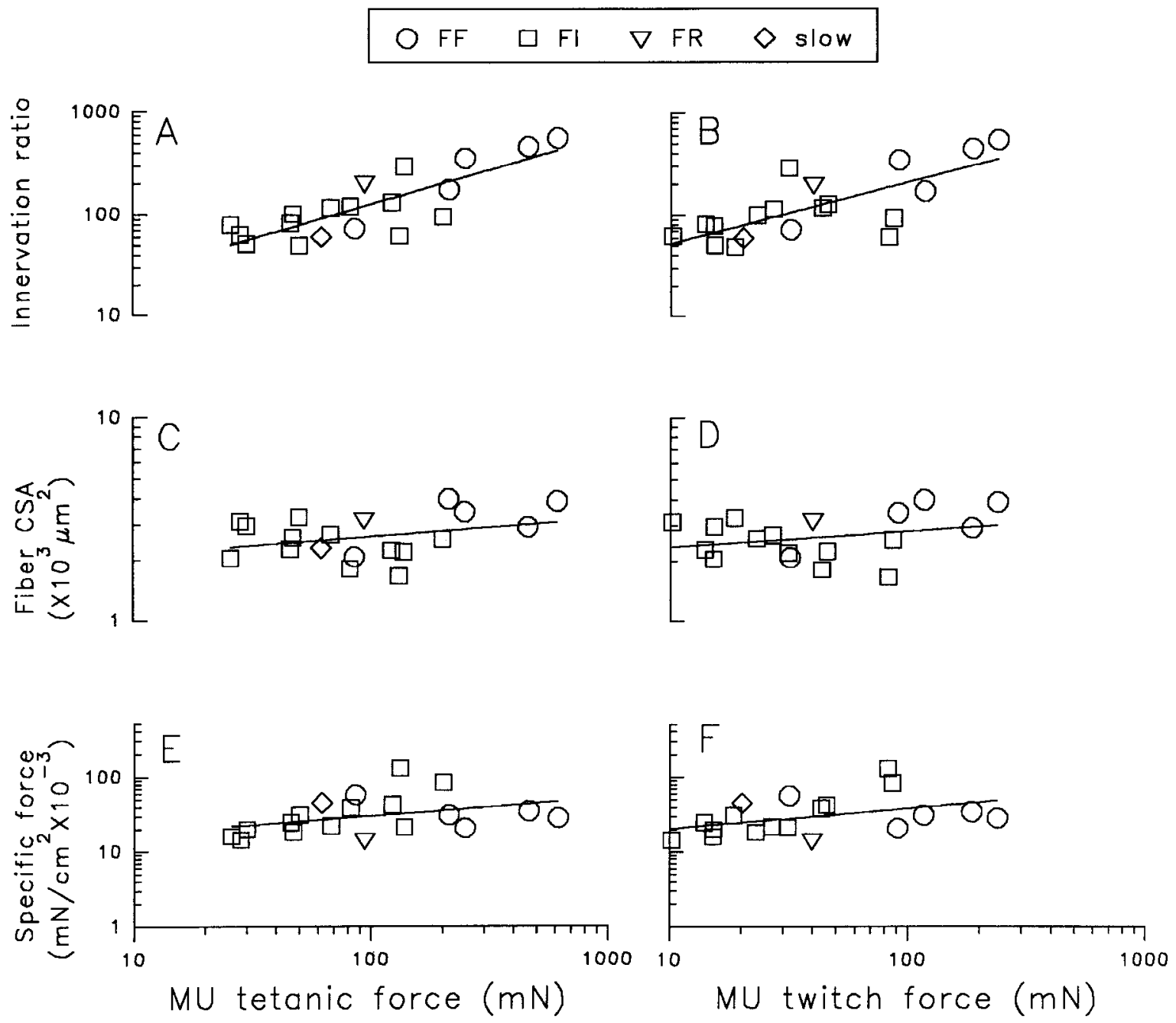

Figure 8. Relationship between the number (innervation ratio, IR), mean cross-sectional area (CSA), and specific force (SF) of the muscle fibers in single MUs and MU tetanic force $(A, C$, and $E)$ and twitch $(B, D$, and $F)$ forces on double logarithmic scales. Regression lines had slopes of $0.60 \pm 0.13$ for IR and tetanic force and $0.67 \pm 0.12$ for IR and twitch force. Two slopes are not different from each other but are significantly different from zero. This shows that MU twitch force is as good as MU tetanic force in representing IR and that the IR is a major contributor to MU force. MU tetanic and twitch forces were not correlated with mean CSA [with slopes ( \pm SE) of $0.07 \pm 0.08$ and $0.1 \pm 0.08$ ] and SF [with slopes ( $\pm \mathrm{SE}$ ) of $0.36 \pm 0.17$ and $0.34 \pm 0.17$, showing that CSA and SF do not contribute significantly to MU force.

regulation of neurofilament protein (Cassar and Tetzlaff, 1991), and expression of the T $\alpha 1$ tubulin isoform normally associated with neuronal growth (Cassar et al,, 1991). However this neuronal growth response may not be sustained long enough to support axonal elongation even in the permissive growth environment in the freshly cut distal nerve stump. Additional contributing factors may include (1) a temporal decline in proliferation and migration of Schwann cells in and from the proximal nerve stump resulting in less effective union of the proximal and distal nerve ends (Holmes and Young, 1942) and (2) a reduced ability of regenerating axons of long-term axotomized motoneurons to respond to the trophic and guidance cues provided by the non-neural cells and extracellular matrix in the freshly denervated nerve stump and target muscles.

The exponential fall in the number of regenerating axons after prolonged axotomy follows the same time course as the reduction in axonal caliber (Gordon et al., 1991). It is not clear whether this coincidence is functionally important, but suggests that axonal atrophy is linked to a decline in its regenerative capacity. Findings that some nerves regenerate successfully and some do not may possibly be linked to differences in the size of motoneurons and their axons that are preserved after axotomy despite atrupliy (Gordon and Stein, 1982).

\section{Compensatory increase in motor unit size}

The increase in both MU force and the number of muscle fibers per motoneuron (IR) clearly indicates that the branching ability of regenerating axons is not compromised by prolonged axotomy. An avcragc of threcfold, with a maximum of fivefold, increase in the number of muscle fibers reinnervated per motoneuron is the same as that of uninjured nerves during sprouting in partially denervated muscles (Brown and Ironton, 1978; Rafuse et al., 1992). Regenerating axons that successfully elongate to reach denervated muscle appear to respond to certain local factors in the intramuscular nerve sheaths and denervated muscle fibers that promote nerve branching and synapse formation. These local factors include the intrinsic cell adhesion molecules that are expressed by Schwann cells within the intramuscular sheaths and denervated muscle membrane and the extrinsic mol- 
ecules of the extracellular basal lamina (Hall and Sanes, 1993; Martini, 1994).

An average of threefold increase in MU size largely compensates for the reduction in the number of reinnervated MUs. As a result, long-term axotomized TIB motor axons reinnervated as many muscle fibers as freshly cut TIB motor axons do, and the reinnervated TA muscles produced as much force as those reinnervated by freshly cut axons. The complete reinnervation of the muscle does not, however, ensure complete motor recovery. Even if misdirection of regenerating nerves was not related to muscle reinnervation (Thomas et al., 1987; Gordon, 1994), the reduced number of MUs would reduce the fine control of movement by MU recruitment that is contingent on a large number of MUs. Interestingly, there was a small but significant increase in slow muscle fibers in the cross-reinnervated muscles that presumably resulted from the overload of the reduced number of functional MUs (Gordon and Pattullo, 1993).

\section{Conclusions}

Prolonged axotomy of motoneurons significantly reduces their ability to regenerate their axons. The capacity of the competent motoneurons to reinnervate more than the normal complement of denervated muscle fibers compensates for a reduction in the number of functional MUs, allowing reinnervated muscles to fully recover. However, in the practical context of delayed nerve repair, prolonged axotomy is inevitably accompanied by prolonged denervation, which further reduces the ultimate number of regenerating axons ( $\mathrm{Fu}$ and Gordon, 1995). The combined effects of prolonged motoneuron axotomy and prolonged denervation of distal nerve stumps and muscle severely compromise the reinnervation of denervated nuscles. The present results, obtained by isolating the effects of prolonged axotomy from prolonged denervation, identify and quantify for the first time the significant reduction in the regenerative capacity of longterm axotomized motoneurons and the contribution of this reduction to the poor motor function after delayed nerve repair.

\section{References}

Aitken JT, Sharman M, Young JZ (1947) Maturation of peripheral nerve fibres with various peripheral connections. J Anat 81:1-22.

Aldskogius H, Arvidsson J (1978) Nerve cell degeneration and death in the trigeminal ganglion of the adult rat following peripheral nerve transection. J Neurocytol 7:229-250.

Arvidsson J, Aldskogius H (1982) Effect of repeated nerve lesions on the number of neurons in the hypoglossal nucleus of adult rats. Exp Neurol 75:520-524.

Birch R, Raji ARM (1991) Repair of median and ulnar nerves: primary suture is best. J Bone Joint Surg 73B:154-157.

Bowden RE, Gutmann E (1944) Denervation and reinnervation of human voluntary muscle. Brain 67:273-313.

Boyd IA, Davey MR (1968) Composition of peripheral nerves. Edinburgh: Livingstone.

Brown MC, Ironton R (1978) Sprouting and regression of neuromuscular synapses in partially denervated mammalian muscles. I Physiol (Lond) 278:325-348.

Carlsson J, Lais AC, Dyck PJ (1979) Axonal atrophy from permanent peripheral axotomy in adult cat. J Neuropathol Exp Neurol 38:579588.

Cassar SL, Tetzlaff W (1991) Chronically axotomized facial motoneurons respond to a second axotomy with increase in tubulin and GAP43 mRNA and decrease in neurofilament mRNA. IIIrd IBRO World Congress Neurosci 29

Cassar SL, Lindsay RL, Maji E, Brdsell DC, Tetzlaff W (1991) Changes in tubulin mRNA in axotomized spinal motoneurons of the adult albino rat. Soc Neurosci Abstr 28.

Crockett DP, Harris SL, Egger MD (1987) Plantar motoneuron columns in the rat. J Comp Neurol 265:109-118.
Dubowitz V, Brooke MH (1973) Muscle biopsy: a modern approach. Philadelphia: Saunders.

Fu SY, Gordon T (1993) A quantitative study of the basis for the poor functional recovery after delayed nerve repair in rats. Fifth international symposium on neural regeneration 28:45.

Fu SY, Gordon T (1995) Contributing factors to poor functional recovery after delayed nerve repair: prolonged denervation. J Neurosci 15:3886-3895.

Fu SY, Raji M, Tyreman N, Gordon T (1993) Does long term axotomy compromise nerve regeneration. Soc Neurosci Abstr 19:423.

Gillespie MJ, Gordon T, Murphy PA (1986) Reinnervation of the lateral gastrocnemius and soleus muscles in the rat by their common nerve. J Physiol (Lond) 372:485-500.

Gordon $T$ (1994) Mechanisms for functional recovery of the larynx after surgery repair of injured nerves. I Voice 8:70-78

Gordon T, Pattullo M (1993) Plasticity of muscle fiber and motor unit types. Sports Exer Sci Rev 21:331-362.

Gordon T, Stein RB (1982) Time course and extent of recovery in reinnervated motor units of cat triceps surae muscles. J Physiol (Lond) 323:307-323.

Gordon T, Gillespie J, Orozco R, Davis L (1991) Axotomy-induced changes in rabbit hindlimb nerves and the effects of chronic electrical stimulation. J Neurosci 11:2157-2169.

Grafstein B, McQuarrie IG (1978) The role of the nerve cell body in axonal regeneration. In: Neuronal plasticity (Cotman $\mathrm{CW}$, ed), pp 155-195. New York: Raven.

Green HL, Reichmann H, Pette D (1982) A comparison of two ATPase based schemes for histochemical muscle fibre typing in various mammals. Histochemistry 76:21-31.

Guth L, Samaha FJ (1970) Procedure for histochemical demonstration of actomyosin ATPase. Exp Neurol 28:365-367.

Gutmann E, Young JZ (1944) The reinnervation of muscle after various periods of atrophy. $J$ Anat 78:15-43.

Gutmann E, Gutmann L, Medawar PB, Young JZ (1942) The rate of regeneration of nerve. J Exp Biol 19:14-44.

Hall SW, Sanes JR (1993) Synaptic structure and development: the neuromuscular junction. Cell 「Suppll 72:99-121.

Himes BT, Tessler A (1989) Death of some dorsal root ganglion neurons and plasticity of others following sciatic nerve section in adult and neonatal rats. J Comp Neurol 284:215-230.

Holmes W, Young JZ (1942) Nerve regeneration after immediate and delayed suture. J Anat 77:63-106.

Jansen JKS, Fladby T (1990) The perinatal reorganization of the innervation of skeletal muscle in mammals. Prog Neurobiol 34:39-90.

Mackinnon S, Dellon L, O'Brien J (1991) Changes in nerve fibre numbers distal to a nerve repair in the rat sciatic nerve model. Muscle Nerve 14:1116-1122.

Martini R (1994) Expression and functional roles of neural cell surface molecules and extracellular matrix components during development and regeneration of peripheral nerves. J Neurocytol 23:1-28.

McComas AJ (1991) Invited review: motor unit estimation: methods Results, and present status. Muscle Nerve 14:585-597.

Melville S, Sherburn TE, Coggeshall RE (1989) Preservation of sensory cells by placing stumps of transected nerve in an impermeable tube. Exp Neurol 105:311-315.

Merle M, Amend P, Cour C, Foucher G, Michon J (1986) Microsurgical repair of peripheral nerve lesions: a study of 150 injuries of the median and ulnar nerves. Periph Nerve Repair Regen 2:17-26.

Parry DJ, Wilkinson RS (1990) The effect of reinnervation on the distribution of muscle fiber types in the tibialis anterior muscle of the mouse. Can J Physiol Pharmacol 68:596-602.

Pearse AGE (1960) Histochemistry theoretical and applied, 2d ed. London: Churchill.

Pullen AH (1977) The distribution and relative sizes of three histochemical fibre types in the rat tibialis anterior muscle. J Anat 123:119.

Rafuse VF, Gordon T, Orozco R (1992) Proportional enlargement of motor units after partial denervation of cat triceps surae muscles. J Neurophysiol 68:1261-1276.

Ramon y Cajal S (1928) Degeneration and regeneration of the nervous system. Reprint (May RM, trans and ed). New York: Hafner, 1959.

Sunderland S (1978) Nerves and nerve injuries. Edinburgh: Livingstone.

Swett JE, Wikholm RP, Blanks RHI, Swett AL, Conley LC (1986) Motoneurons of the rat sciatic nerve. Exp Neurol 93:227-252. 
Terzis JK, Smith KL (1990) The peripheral nerve: structure, function and reconstruction. New York: Raven.

Thomas CK, Stein RB, Gordon T, Lee R, Elleker G (1987) Patterns of reinnervation and motor unit recruitment in human hand muscles after complete ulnar and median nerve section and resuture. $J$ Neurol Neurosurg Psychiatry 50:259-268.

Toft PB, Fugleholm K, Schmalbruch H (1988) Axonal branching following crush lesions of peripheral nerves of rats. Muscle Nerve 11: $880-889$.

Tötösy de Zepetnek JE, Zung HV, Erdebil S, Gordon T (1992a) In- nervation ration is an important determinant of force in normal and reinnervated rat Tibialis Anterior muscles. J Neurophysiol 67:13841403.

Tötösy de Zepetnek JE, Zung HV. Erdebil S, Gordon T (1992b) Motor unit categorization on the basis of contractile and histochemical properties: a glycogen depletion analysis of normal and reinnervated rat tibialis anterior muscles. J Neurophysiol 67:1404-1415.

Watson WE (1970) Some metabolic responses of axotomized neurons to contact between their axons and denervated muscles. J Physiol (Lond) 210:321-343. 